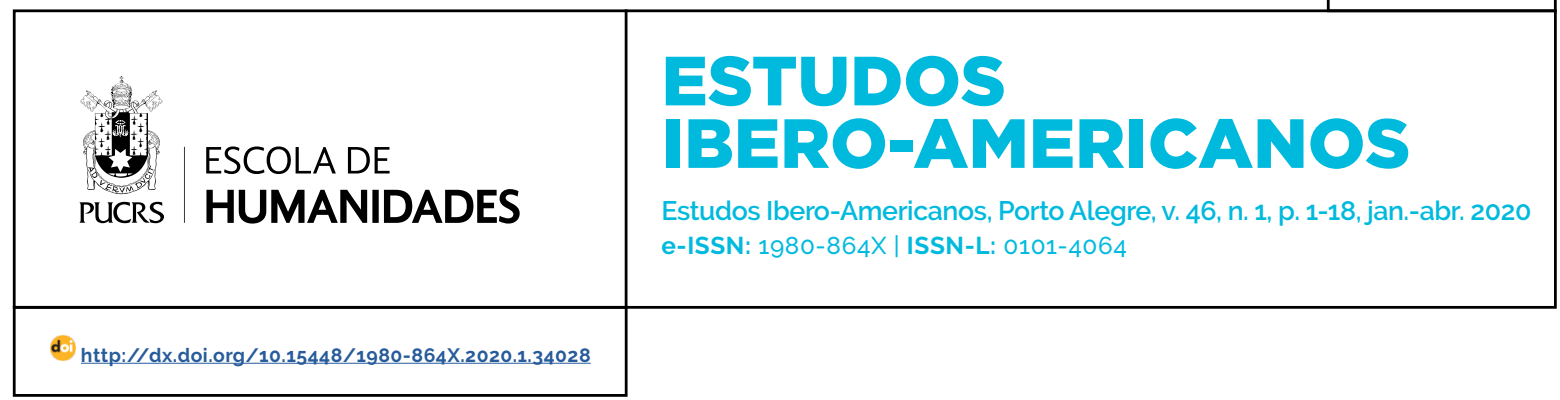

SEÇÃO: DOSSIÊ

\title{
Paisagens e fronteiras do Cerrado: ciência, biodiversidade e expansão agricola nos chapadões centrais do Brasil
}

\author{
Landscapes and frontiers: science, biodiversity and agricultural expansion at the \\ Cerrado in Central Brazil \\ Paisajes y fronteras del Cerrado: ciencia, biodiversidad y expansión agrícola en las \\ chapas centrales de Brasil
}

Sandro Dutra e Silva ${ }^{1,2}$ orcid.org/0000-0002-0001-5726 sandrodutr@hotmail.com

\section{Altair Sales Barbosa ${ }^{2}$ \\ orcid.org/0000-0003-4422-4922 altairsalesbarbosaf@gmail.com}

Recebido em: 5 jul. 2019 Aprovado em: 11 out. 2019 . Publicado em: 28 abr. 2020.
Resumo: Este artigo tem por finalidade apresentar a história ambiental do Cerrado como um sistema biogeográfico e as consequências ambientais da expansão da fronteira agrícola na região central do Brasil. A pesquisa está embasada em um conjunto diverso de fontes documentais e bibliográficas que ressaltam as paisagens do Cerrado, sua biodiversidade, com ênfase nos processos históricos da expansão da fronteira agrícola. O estudo está fundamentado nos pressupostos teórico-metodológicos da história ambiental para a compreensão da relação entre sociedade e o ecossistema do Cerrado. Os resultados apontam que a compreensão do Cerrado como sistema biogeográfico é complexa e os diferentes processos históricos de percepção, descrição e ocupação desse ecossistema acontece de forma variada, considerando a diversidade das paisagens e dos elementos naturais que o compõe. Ademais, os esforços governamentais no desenvolvimento científico para tornar o Cerrado como fronteira agricola, bem como a expansão agropecuária dos últimos 50 anos têm alterado significativamente as suas paisagens, gerando impactos e danos ambientais irreversiveis nesse ecossistema único nos chapadões centrais da América do Sul.

Palavras-chave: História ambiental. Savana brasileira. Brasil Central. Fronteira agrícola.

Abstract: This article aims to present the environmental history of the Cerrado (the Brazilian tropical savannah) as a biogeographic system and the environmental consequences of the agricultural frontier expansion in central Brazil. The research based on a diverse set of documentary and bibliographic sources that highlight the Cerrado landscapes, its biodiversity, with emphasis on the historical processes of agricultural frontier expansion. This is a theoretical-methodological assumption of environmental history study to understand the relationship between society and the Cerrado ecosystem. The results show the understanding of the Cerrado as biogeographic system is complex and the different historical processes of perception, description and occupation of this ecosystem happens in a varied way, considering the landscapes diversity and the natural elements that compose it. In addition, the governmental efforts in scientific development to make the Cerrado an agricultural frontier as well as the agricultural expansion of the last 50 years have significantly changed its landscapes, generating impacts and irreversible environmental damage to this unique ecosystem in the central plateaus of South America South.

Keywords: Environmental history. Brazilian savannah. Central Brazil. Agricultural frontier.

Resumen: Este artículo tiene como objetivo presentar la historia ambiental del Cerrado (la sabana tropical brasileña) como un sistema biogeográfico y las consecuencias ambientales de la expansión de la frontera agrícola en el centro de Brasil. La investigación se basó en un conjunto diverso de fuentes documentales y bibliográficas que destacan los paisajes del Cerrado, su biodiversidad, con énfasis en los procesos históricos de expansión de la frontera agricola. Est es un estudio teórico-metodológico del historia ambiental para comprender la relación entre la 
sociedad y el ecosistema del Cerrado. Los resultados muestran que la comprensión del Cerrado como sistema biogeográfico es compleja y los diferentes procesos históricos de percepción, descripción y ocupación de este ecosistema ocurren de manera variada, considerando la diversidad de paisajes y los elementos naturales que lo componen. Además, los esfuerzos gubernamentales en el desarrollo cientíico para hacer del Cerrado una frontera agrícola, asi como la expansión agrícola de los últimos 50 años han cambiado significativamente sus paisajes, generando impactos y daños ambientales irreversibles a este ecosistema único en las mesetas centrales del Sudamérica.

Palabras clave: Historia ambiental. Sabana brasileña. Brasil Central. Frontera agrícola.

\section{Introdução}

São vários e sobremodo importantes os registros sobre a história das paisagens do Cerrado nos chapadões centrais do Brasil. E muitos desses valorosos registros estão relacionados aos diferentes processos de ocupação da fronteira histórica no Brasil Central. Esses diferentes registros nos auxiliam na compreensão histórica de um dos ecossistemas mais antigos e ameaçados do planeta, sobretudo a partir da expansão da fronteira agrícola ocorrida na segunda metade do século XX. Assim, nosso objetivo é apresentar a história ambiental do Cerrado como um sistema biogeográfico. Uma história ambiental do Cerrado torna-se um desafio monumental, na medida em que as temporalidades envolvidas vão muito além da presença humana nesse ecossistema. Assim, um diálogo com outras áreas do conhecimento nos auxilia a descrever as características do Cerrado como um sistema biogeográfico (BARBOSA, 2002) e que favoreceram processos de expansão da fronteira. No entanto, neste estudo procuramos identificar, principalmente, o contexto histórico da fronteira agricola ocorrida após a década de 1970, que coincidem com os processos globais da grande aceleração. Os processos de grande aceleração, que segundo McNeil e Engelke (2014) são marcas do que eles definem como o antropoceno. Ela se caracteriza pelo ritmo acelerado do uso de energia, das emissões de gases de efeito estufa e do crescimento da população, levando o planeta, a partir da segunda metade do século XX, a um ritmo descontrolado de impactos ambientais.

Um fato que nos auxilia no exercício da perplexidade histórica sobre o Cerrado é a percepção do rápido a avassalador processo de ocupação e destruição das paisagens naturais. Dentre as finalidades de uma história ambiental do Cerrado está o de descrever como esses processos de expansão da fronteira são ameaçadores, principalmente no que se refere à extinção de espécies, ao extermínio de uma fitofisionomia que evolui desde o período Cenozoico. Seu valor histórico e a proteção deste ecossistema vão além da preservação das belezas estéticas das paisagens savânicas do Brasil Central. Seu valor se deve, em grande medida pela intangivel riqueza de sua grande biodiversidade (PEIXOTO et al., 2019).

A presença humana nesse ambiente tão antigo deixou registros e que as pesquisa arqueológicas nos ajudam a descrever. Destacamos o importante trabalho Bachelet (2014) a partir do estudo de macrorrestos de vegetais carbonizados descobertos em contexto arqueológico. Sua pesquisa fornece importantes resultados sobre o comportamento humano no Brasil Central datados do final do Pleistoceno até o Holoceno. Esse estudo aponta, ainda, a partir das identificações taxonômicas, os diversos aspectos da utilização dos recursos vegetais pelos grupos humanos de caçadorescoletores e a paleovegetação ao redor dos sítios arqueológicos. Os resultados arqueológicos apontam que esses grupos humanos praticavam uma coleta de lenha oportunista nas formações vegetais próximas aos abrigos, e principalmente privilegiavam a utilização de madeira seca. De forma importante, os estudos arqueológicos apontam que durante o Holoceno a paisagem e o clima dos chapadões centrais do Brasil eram semelhantes aos padrões atuais, apresentando uma fitofisionomia típica do que atualmente consideramos como sendo o bioma Cerrado, com o mesmo padrão climático tropical sazonal (BARBOSA, 2002).

No entanto, a partirdo acelerado processo de trocas culturais em torno de cinco séculos de colonização e da expansão das fronteiras europeias sobre o novo mundo (HOLANDA, 2010) - processo esse descrito por Crosby (1972, 2009) como imperialismo ecológico ou intercâmbio colombiano - os recursos naturais do Cerrado passaram a ser cobiçados e explorados. $O$ conceito de fronteira (TURNER, 2010; WEBB, 2003; 
WORSTER, 1992), caro para a historiografia norteamericana, é um referencial fundamental para a compreensão dos processos históricos de ocupação do Cerrado. Diferentes fronteiras (HENNESSY, 1978), motivadas por variados recursos naturais e em temporalidades distintas marcaram o processo de ocupação do Cerrado (MCCREERY, 2006, KARASCH, 2016; DUTRA E SILVA, 2017). As paisagens dos chapadões centrais do Brasil foram drasticamente transformadas pelas diferentes frentes de ocupação demográfica e geográfica do Cerrado DUTRA ESILVA 2017; GIUSTINA, 2013; GIUSTINA; DUTRA E SILVA; MARTINS, 2018). A introdução de espécies exóticas como gramineas africanas e cultivares valorizadas no mercado global de alimentos e energia dominam as paisagens do Brasil Central (DUTRA E SILVA et al., 2015; VAN AUSDAL; WILCOX, 2013; WILCOX, 2017). Os estudos relacionados à expansão da fronteira agrícola no Cerrado apontam que pouco restou da fisionomia original desse bioma (DUTRA E SILVA et al., 2018; STRASSBURG et al., 2017). Ainda restam algumas manchas de vegetação original, com fisionomia já bastante descaracterizada, cujos remanescentes mais significativos encontram-se em unidades de conservação ou em áreas onde a sua exploração do agronegócio é prejudicada em função das caracteristicas do relevo (SANO et al., 2007; FERREIRA et al., 2016).

Como Clarence Glacken (1967) nos alertou, a natureza foi sempre uma categoria central do pensamento humano, sobretudo na cultura ocidental, desde a Antiguidade. As perplexidades (SANTOS, 1997) e as problematizações apresentadas são muito mais complexas e extrapolam o métier historiográfico. Mas, ao mesmo tempo, esse desafio da historiografia em lidar com o mundo natural já foi exaustivamente justificado e fizeram parte, inclusive, da consolidação da história ambiental como campo historiográfico distinto (WORSTER, 1988; PÁDUA, 2012).

\section{As paisagens do Cerrado: registros da história geológica do planeta}

As paisagens podem ser tomadas pelo historiador como um documento privilegiado para a história ambiental (MARTINS, 2007). E uma história ambiental do Cerrado pode ser reveladora em vários sentidos. Não apenas na relação entre história e natureza, mas na própria história da natureza. Cronon (1991), defendendo a importância da interface entre as ciências da natureza e a história, afirma que a geologia, a ecologia e a clássica historiografia humana, são todas, de alguma forma, uma ciência histórica. Para ele, o que torna esses campos do conhecimento como um campo histórico é a sua relação com o processo evolutivo das paisagens. Em outras palavras, são ciências que lidam com as transformações históricas das paisagens. Ou, acompanhando Marcos Lobato Martins (2007), as paisagens são, simultaneamente objeto e documento histórico.

A geologia, por exemplo, pode ser considerada como uma ciência histórica da paisagem, cujo campo de atuação analisa, principalmente, processos físicos e biológicos do ambiente natural (DUTRA E SILVA, 2019). Nesse sentido, uma postura fundamental recomendada está na ampliação da objetiva para outras disciplinas (DRUMMOND, 1991), sobretudo quando identificamos a importância de compreender o Cerrado dentro da história geológica do planeta (BARBOSA, 2002).

O Cerrado é um dos mais antigos sistemas biogeográficos e que evoluiu durante história recente do planeta, ocorrida no periodo Cenozoico há pelo menos 65 milhões de anos (BARBOSA, 2019). O Cerrado se concretizou neste ambiente biofísico específico nos chapadões centrais da América do Sul por volta de 40 a 45 milhões de anos antes do presente (NEVES; CORDANI, 1991; LAUX et al., 2005). Assim, é fundamental o papel da história ambiental nos estudos em ciências ambientais e nas áreas correlacionadas por evidenciar às limitações que conceitos dominantes e amplamente difundidos. Dentre esses conceitos destacamos os biomas. Quando pensamos em longa duração e nos tempos geológicos podemos considerar que o conceito de bioma simplifica, em grande medida, a compreensão dos espaços biofísicos (COUTINHO, 2006). Segundo Coutinho (2011), o uso desse conceito no Brasil adquiriu erroneamente uma conotação florística, quando na verdade, seu uso e muito mais amplo e complexo. Por isso, ele advoga que, se fossemos considerar o uso 
do conceito de bioma para as formações de cerrado lato sensu, haveria a formação de três biomas distintos, a saber, o campo tropical, a savana e a floresta estacional. Por essa razão procuramos nos fundamentar nas assertivas conceituais que caracterizam o Cerrado como um "sistema biogeográfico" (BARBOSA, 2002), ao considerar todos os elementos naturais que estão intimamente interligados nesse ecossistema.

o Cerrado como um sistema biogeográfico não pode ser considerado apenas pelo seu escopo vegetacional, caracterizado por um gradiente variante que se expressa desde campo totalmente aberto (ou um ambiente de claridade), até o ambiente ombrófilo (um gradiente cerrado/fechado), que compreende as formações florestais. Em termos de vegetação o Cerrado é esse mosaico de paisagens cuja modificação em quaisquer desses ambientes provoca mudanças nos demais ambientes vegetais como um todo (BARBOSA, 2002).

Considerando a diversidade da fauna e flora, - Cerrado pode ser classificado como uma das maiores biodiversidades do mundo, em interação entre os diferentes elementos naturais que caracterizam esse sistema biogeográfico (BARBOSA, 2002). A fauna existe em simbiose com a flora do Cerrado. A aniquilação de algumas espécies de animais pode comprometer a germinação e, em alguns casos, a extinção de espécies vegetais. Um exemplo dessa simbiose é Araticum do Cerrado (Annona coriacea), uma planta da familia Anonaceae, e que recebe diferentes designações populares, como por exemplo, araticum rasteiro, araticum do mato ou marolo de moita. Essa planta foi classificada por Martius e está descrita na Flora brasiliensis (Figura 1). A germinação da Annona coriacea ocorre somente após o fruto passar pelo intestino delgado de algum canídeo nativo do Cerrado. Assim, a extinção de canídeos nativos como o lobo guará, o cachorro do mato ou a raposa campestre. impacta diretamente na preservação de espécies vegetais, evidenciando a complexidade do sistema biogeográfico do Cerrado (BARBOSA, 2002). O mesmo ocorre com a espécie Solanum lycocarpum A.St.-Hil, pertencente à familia Solanaceae e conhecida popularmente como lobeira, fruta do lobo e lobeira brava. Essa planta foi classifica por Saint-Hilaire e está descrita na Flora Brasiliensis e na obra do Herbário Virtual de Saint-Hilaire. Ambas as espécies citadas - Annona e Solanum - foram coletadas nos chapadões centrais do Brasil e comprovam a complexidade na relação de co-evolução flora/fauna. ${ }^{2}$

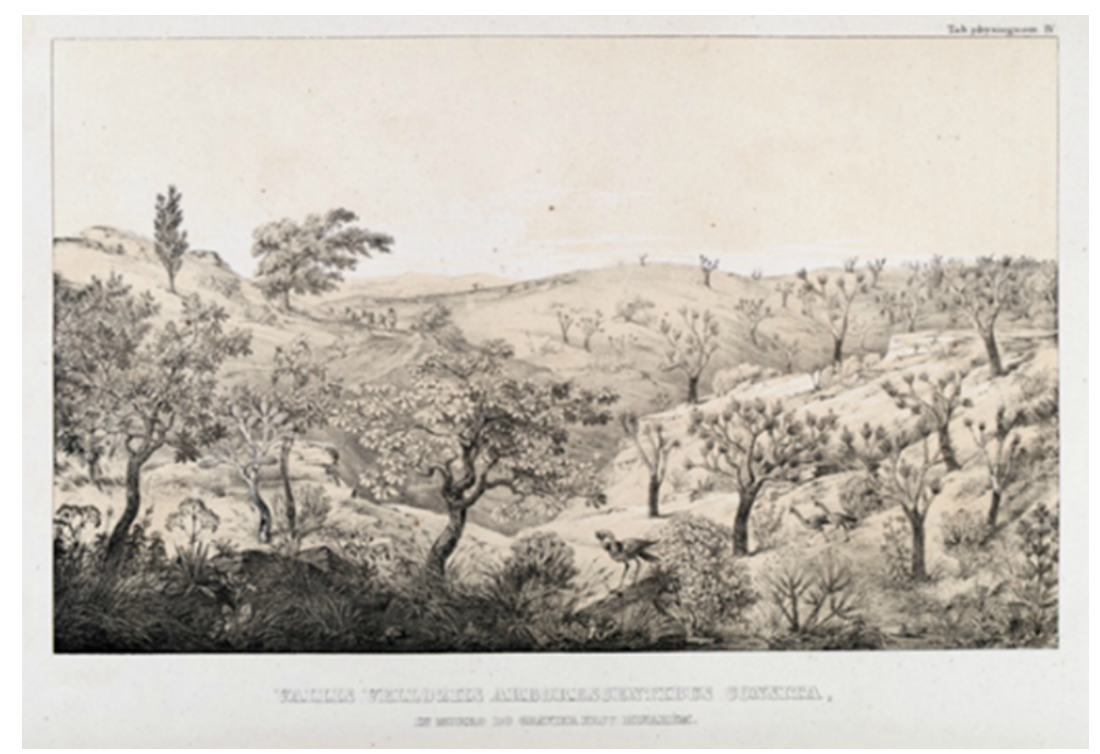

Figura 1 - Annona coriacea. Familia Annonaceae, Carl Friedrich Philipp von Martius [Mart.], Gênero Annona L., Seção Guanabani L., Annona coriacea Mart

Fonte: Flora Brasiliensis, v. 13, Part 1, p. 6-7.

\footnotetext{
2 Herbário Virtual Auguste de Saint-Hilaire, onde consta a obra e espécimes coletadas, classificadas e identificadas na forma de exsicatas. Disponivel em: http://hvsh.cria.org.br. Acesso em: 15 mar. 2019
} 
Esse sistema também se aplica a grupos de insetos polinizadores do Cerrado, que evoluiram, anatomicamente, e de forma apropriada para a polinização de espécies vegetais (GOTTSBERGER, 1989, 2016; GOTTSBERGER, G.; SILBERBAUERGOTTSBERGER, 2006). A subtração desses grupos de insetos fundamentais na zoofilia, principalmente por meio da expansão da fronteira agricola, que vem acompanhada pelo uso indiscriminado de agrotóxicos e outros pesticidas muito utilizados no cultivo da soja, por exemplo, eliminam os polinizadores potenciais de diversas espécies nativas do Cerrado (CAMARGO et al., 2018).

Outra variável desse componente biofísico é o seu padrão climático. O cerrado é um tipo de ambiente que tem um padrão climático estabelecido há quase 45 milhões de anos antes do presente, e que substantifica a sua sazonalidade estacional. Esse padrão climático é sedimentado de forma mais densa a partir do início do pleistoceno quando houve a glaciação no hemisfério norte que afetou muito pouco a região dos cerrados em termos climáticos (GALVÃO, 1960 e 1962; HARGREAVES, 1976; AB'SABER, 2000; ASSAD, 1994; SILVA et al., 2008).

O fogo também é outro elemento natural que está associado à história biofísica do Cerrado (GOMES et al., 2014; GOMES, MIRANDA; BUSTAMANTE, 2018; COUTINHO, 1977; HENRIQUES, 2005). Esse é um tema complexo e polêmico, sobretudo para os pesquisadores acostumados aos eventos de incêndio característicos dos regimes de fogo contemporâneos. No entanto, o fogo natural foi um elemento responsável pela formação e existência do Cerrado. Ele pode ocorrer de forma espontânea, por exemplo, quando um cristal de quartzo recebe uma incidência solar mais intensa que reflete em uma gramínea nativa seca nos meses de agosto e setembro, que são os meses de maior incidência das queimadas. Os ecologistas têm afirmado que a queimada natural tem impactos positivos tanto na fauna quanto na flora do cerrado. A alteração no regime de fogo, sobretudo a partir da introdução de gramineas exóticas africanas como o capim-gordura ou a braquiária, que atualmente dominam as paisagens do Cerrado (DUTRA E SILVA et al., 2015: BROOKS et al., 2004; MIRANDA, BUSTAMANTE; MIRANDA, 2002; SAINT-HILAIRE, 1975), é um tema importante, problemático do ponto de vista ambiental e muito pouco estudado pelos historiadores ambientais.

\section{As paisagens do Cerrado nas descrições naturalistas}

Na relação entre a história das paisagens e a ocupação da fronteira, destacamos o trabalho singular dos naturalistas europeus. Orientados pelo espírito cientificista no século XIX, amplamente difundido na Europa pelas viagens de Humboldt (WULF, 2015), os viajantes naturalistas construiram coleções e um conjunto documental de informações que compõem registros privilegiados sobre as paisagens e as fronteiras do Cerrado (MARTIUS, 2015; SPIX; MARTIUS, 1981; SAINTHILAIRE, 1975; GARDNER, 1975; POHL, 1976). Muitos desses registros ocupam importantes museus de História Natural espalhados em diferentes regiões do planeta. E ao mesmo tempo, descrições botânicas, coleções zoológicas, arqueológicas e geológicas nos ajudam a compreender o valor histórico dos chapadões centrais do Brasil, bem como a reais ameaças à biodiversidade e à conservação desse importante patrimônio natural.

Além das coleções e coletas de espécimes botânicas e zoológicas, os naturalistas deixaram descrições e impressões da cultura dos povos que viveram nos chapadões centrais do Brasil. As descrições sobre a vegetação por exemplo, decorrem do olhar atento do naturalista. 0 conceito de fitofisionomia, que é uma característica morfológica da comunidade vegetal, foi empregado originalmente por Humboldt para descrever a vegetação (GRABHERR; KOJIMA, 1993) e as paisagens identificadas durante suas expedições. Duas das mais importantes expedições científicas sobre as paisagens e fitofisionomia do Cerrado datam do início do século XIX, quando os naturalistas Johann Baptist Emanuel Pohl (1782-1834) e Auguste de Saint-Hilaire (1779-1853) percorreram os chapadões centrais do Brasil (POHL, 1975; SAINT-HILAIRE, 1975). 
A expedição coordenada pelo médico e botânico J. E. Pohl foi responsável pela coleta de um rico material, que resultou no importante Plantarum Brasiliae Icones et Descriptiones hactenus ineditae, publicado em dois volumes, em 1826 e 1833 (POHL, 1976). Além de Pohl, as expedições ocorridas nos chapadões centrais do Brasil incluiam os pesquisadores Johann Mika, o taxidermista Johann Natterer e o pintor de paisagens Thomas Ender. Parte do material coletado está depositado no Museu de História Natural de Viena (Naturhistorisches Museum Wien), compondo um material denominado de expedições do século XIX, com uma especifica designação de expedição à floresta tropical brasileira (expedition in die regenwälder brasiliens). Importante, no entanto, é que apesar desta expedição ter coletado formidável material das florestas brasileiras, com destaque para o bioma Mata Atlântica, muito das coleções sobre fauna e flora do Cerrado compõem essas coletas cientificas (ADAM, 2005: RIEDL-DORN, 1999).

O botânico francês Saint-Hilaire, retornou à França com material coletado e com publicações que ele apresentou ao Museu de História Natural de Paris. Seus relatos de viagem e suas notas cientificas resultaram em importantes publicações. Em 1824, ele publicou a obra Histoire des plantes les plus remarquables du Brésil e du Paraguay e. posteriomente o livro Plantes usuelles des Brasiliens (1824-1828) e Flora Brasilae Meridionalis (18251833). Alexander von Humboldt foi o rapporteur de seu trabalho na Academia de Ciências de Paris em 1824 e em 1825. De acordo com os Annales des Sciences Naturelles, Humboldt fez elogios à importante pesquisa e à coleção botânica que Saint-Hilaire trouxe do Brasil para a França. Em 1830, após publicar um conjunto importante de trabalhos com criticas muito favoráveis, SaintHilaire foi aceito como membro da Academia de Ciências de Paris (KURY, 2003).

O botânico, médico e antropólogo alemão Carl F. von Martius (1794-1868) e o artista francês Hercule Florence (1804-1879) foram responsáveis por um dos mais importantes registros visuais sobre o Cerrado (Figura 2). De acordo com Oliveira (2017) esses registros foram apreendidos com uma peculiaridade que denotavam a estranheza, a poesia e a admiração das paisagens descritas (OLIVEIRA, 2017). Esses viajantes naturalistas, que visitaram o Brasil Central no ano de 1819, acompanhados do zoólogo Johann Baptist von Spix (1781-1826), registraram a diversidade da fitofisionomia dos chapadões centrais do Brasil (SPIX; MARTIUS, 1981). Spix e Martius publicaram em 1823 a obra Reise in Brasilien, posteriormente traduzida para a lingua portuguesa como Viagem pelo Brasil (SPIX; MARTIUS, 1981). E com base em suas coletas no Brasil publicaram Nova Genera et Species Plantarum e Historia Naturalis Palmarum (SPIX; MARTUIUS, 1981).Em 1840 começou a ser publicada a obra Flora Brasiliensis - e que foi finalizada apenas em 1906 - que descreve 22.767 espécies do conjunto da flora brasileira conhecida no século XIX3.

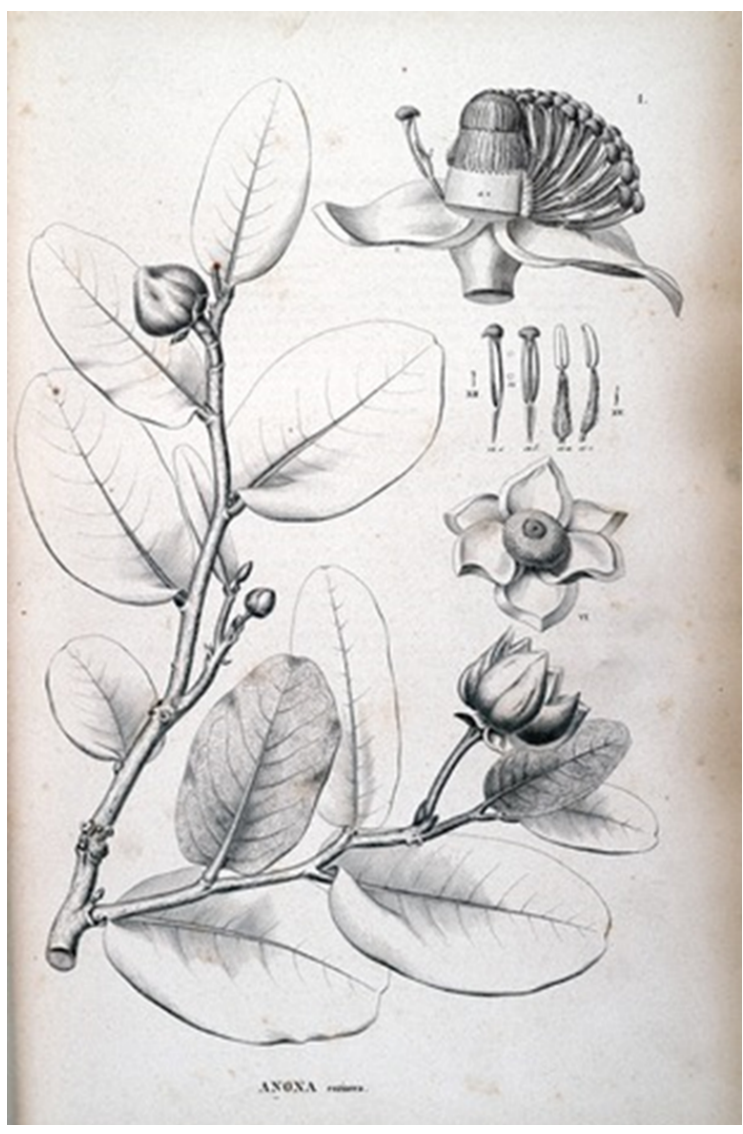

Figura 2 - Prancha de uma área de cerrado de Minas Gerais no século XIX, de von Martius

Fonte: Flora Brasiliensis, volume I, 1906. 
Segundo Oliveira (2017) a importância dos registros que compõem a Flora Brasiliensis está no valor documental das narrativas e das imagens. As descrições paisagísticas são fundamentais ao considerar que elas compõem informações visuais valiosas, tanto para as ciências naturais, como também para os historiadores ambientais, da arte, da história das ciências, dentre outros.

Em uma outra importante descrição, realizada há poucas décadas depois dos naturalistas mencionados anteriormente, o botânico dinamarquês Eugenius Warming (1841-1924), publicou na Revista Popular para Divulgação das Ciências Naturais, de Copenhague, as suas impressões sobre a natureza do Brasil tropical (GOMES, 2006). Os registros datam do início do mês de maio do ano de 1863, quando Warming fazia um roteiro que havia se iniciado no Rio de Janeiro em direção à Lagoa Santa, Minas Gerais. Um roteiro que incluia a passagem pela exuberância dramática da Mata Atlântica e de suas florestas tropicais de altitude. Na Serra da Mantiqueira, quando atravessava o ambiente ombrófilo dominado pela Araucaria brasiliensis (nome científico: Araucaria angustifolia (Bertol.) Kuntze Araucariaceae), percebeu que logo adiante uma nova paisagem se descortinava para ele. Foi o seu primeiro contato com o Cerrado. Nos chama atenção em seus relatos, que diferente da decepção aparente de Saint-Hilaire com o Brasil Central, Warming se mostrou muito mais entusiasmado. Assim ele descreveu a sua fascinação com esse ambiente, que iria ser fundamental para a sua trajetória acadêmica no campo da História Natural, principalmente, nas descrições botânicas do Cerrado brasileiro.

O trabalho de Warming representou um marco definitivo nos estudos do Cerrado brasileiro, pois em 1892 ele publicou na Dinamarca a obra Lagoa Santa. Et Bidrag til den biologiske Plantegeografi, traduzida em 1908 para a língua portuguesa pelo botânico Alberto Löfgren (WARMING, 1892; KLEIN, 2002). O trabalho de Warming incluia, além dos estudos realizados no cerrado mineiro, exsicatas coletadas em Lagoa Santa, fotografias, desenhos à lápis das paisagens do Cerrado (Figura 3) e de orquideas coletadas em campo, além de outras anotações que compõem importante acervo no Museu Botânico da Universidade de Copenhague, cujo herbário (Herbarium Eug. Warming) lega o nome do naturalista dinamarquês.

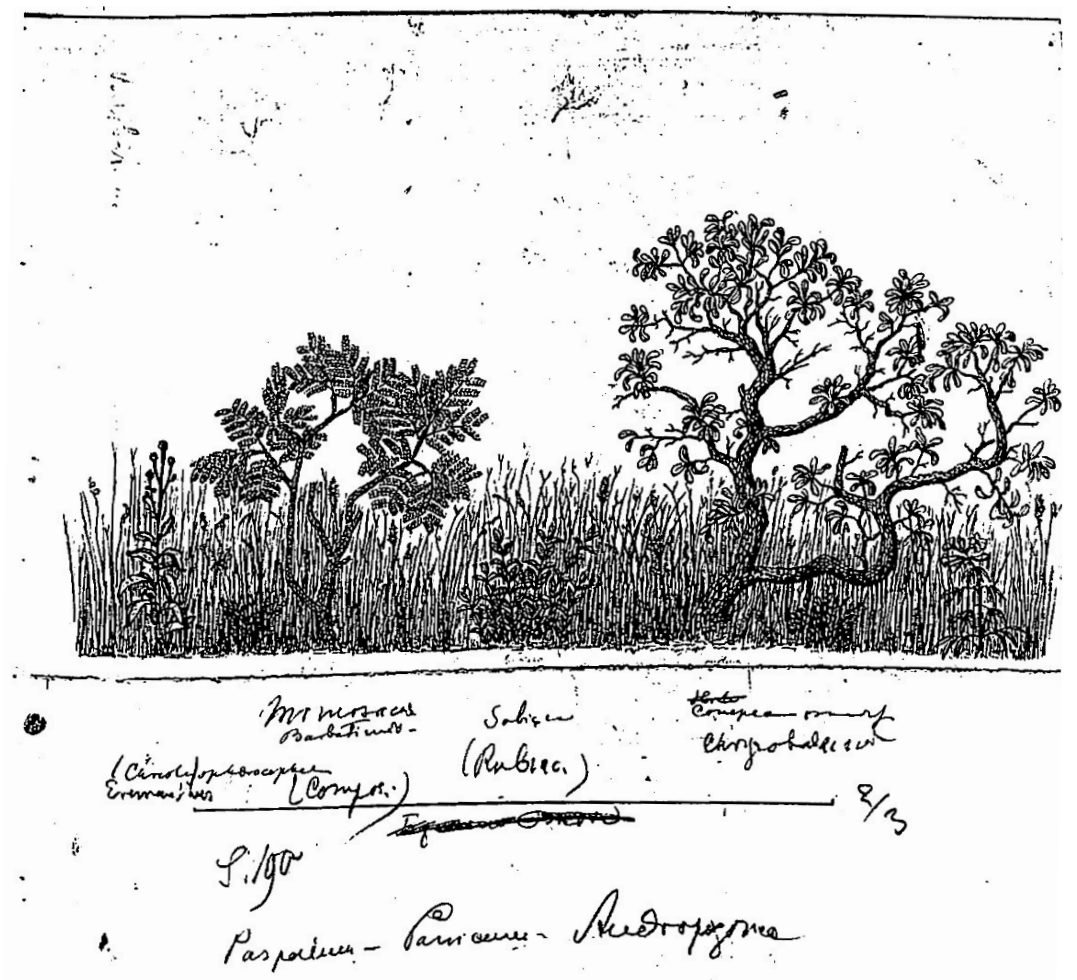

Figura 3 - Desenhos a lápis feitos por Eugenius Warming sobre as paisagens do Cerrado Fonte: Natural History Museum of Denmark (archives). 
As descrições das fitofisionomias do Cerrado realizadas pelos naturalistas são fontes privilegiadas para a história ambiental desse ecossistema, na medida em que esses registros indicam as transformações ocorridas nas paisagens. Ao mesmo tempo, como nos orientou Warren Dean (1995), as descrições das paisagens realizadas pelos naturalistas oitocentistas não devem ser tomadas como fonte fidedignas da fitofisionomia das regiões visitadas. Para ele, muito dos registros e coleções descritas foram produzidas em locais de maior facilidade de acesso. Ao mesmo tempo, não podemos desprezar o conteúdo ideológico dos registros feitos pelos naturalistas e as adversidades e estranhamentos com o ambiente exótico e indômito dos cerrados (SOUZA, 2015; KURY, 2001). Importante destacar que as paisagens naturais mudam, como mudam, também, a nossa percepção em relação a elas. As paisagens representam as evoluções naturais, como também elas decorrem das experiências sensoriais das sociedades humanas. Elas sofrem alterações por conta das estações que periodicamente interferem em seu ciclo natural, como também da percepção humana dessas transformações.

A temporalidade é outro fenômeno que interfere nas paisagens naturais, tendo sua maneira própria de marcar o tempo. No Cerrado essa temporalidade é marcada por dois grandes eventos: o período chuvoso e a estiagem. E assim o ciclo de alterações, mudanças e transformações caminham: ora tempo de chuva, ora tempo de seca. Ora inverno, ora verão. Ora tempo das flores, ora as folhagens se vestem de um verde intenso. Ora a vegetação queima ao fogo, deixando um rasto de cinza e devastação. Ora águas e mananciais brotam, correndo vagarosamente em meio a pedregulhos em uma calmaria que rompe a dramaticidade do cenário hostil. Ora os redemoinhos de vento arrastam as folhas secas e o pó da terra na aridez dos meses de agosto e setembro. E assim as paisagens seguem o seu ritmo cíclico da natureza e de suas temporalidades.

Cultura e natureza se misturam no drama evolutivo das transformações das paisagens que podem significar mudanças profundas no ambiente e em um ritmo sem precedentes. E esse é o grande desafio para se fazer uma história ambiental do Cerrado. Isso porque, assim como qualquer ecossistema, as questões não são exclusivas de suas particularidades intrinsecas, mas também interacionais. Todos os ambientes são ambientes interacionais. E essa complexidade é ainda maior quando pensamos no exercício historiográfico em lidar com esses processos, mesmo considerando que a temática da natureza não é um produto exclusivo das discussões ambientais na cultura contemporânea. No entanto, o fenômeno da fronteira agrícola, como veremos adiante, tem trazido mudanças profundas nas paisagens, no uso do solo, nos recursos hídricos, causando danos irreparáveis no sistema biogeográfico do Brasil Central.

\section{A fronteira agricola e a transformação das paisagens do Cerrado}

Em relação às paisagens e as fronteiras, uma história ambiental do Cerrado deve considerar essa complexa interação entre sociedade e natureza na expansão demográfica da fronteira e nas formas de apropriação dos diferentes recursos naturais que constituiram a própria construção e delimitação desse ambiente (SILVA, 2018). A história dos usos dos conceitos, das delimitações territoriais, do mapeamento, dos caminhos e assimilação de fitofisionomias e paisagens são exemplos dessa complexa relação. Lidar com os conceitos em escala histórica é um complexo exercício para o historiador ambiental, sobretudo quando consideramos a sua designação dos biomas como um fenômeno histórico recente. Coutinho (2006) nos chama atenção para o uso inadvertido de certos conceitos que tem aparecido cada vez com mais frequência nos artigos científicos. Conceitos como domínios morfoclimáticos, sistemas biogeográficos, biomas, dentre outros, nem sempre vêm acompanhados dos sentidos originais dos termos, criando, assim, uma grande confusão conceitual. Para ele quase sempre os conceitos não coincidem entre si, ou com aqueles empregados nos meios científicos.

A história da constituição dos conceitos é 
complexa e domínio de áreas diferentes do campo historiográfico tradicional. No entanto, o historiador precisa lidar não apenas com os conceitos, mas com o uso político deles, na medida em que os usos apontam para intencionalidades diversas. Um exemplo disso é o mapeamento dos biomas brasileiros. A publicação dos mapas dos biomas brasileiros pelo Instituto Brasileiro de Geografia e Estatística (IBGE) foi apenas em 2004, decorrente do mapa de vegetação e com base nos projetos do Radam e Sivam.

Desta forma, a história ambiental do Cerrado não pode desconsiderar as assimilações e os diferentes interesses que associam o advento histórico da fronteira agricola e as delimitações territoriais dos biomas brasileiros. Isso porque, o conceito de "fronteira agrícola" está associado a um tipo particular do uso da terra, intensificado com o emprego da tecnologia na produção de alimentos.

Os processos de expansão da fronteira agrícola no Cerrado devem considerar o conjunto de transformações e investimentos em diferentes temporalidades e espacialidades. São processos decorrentes de uma dinâmica ampla, cujas origens estão na própria história dos deslocamentos de outras frentes históricas. O Cerrado como potencial agricola na produção de commodities foi um fenômeno histórico importante, em que a compreensão do espaço físico como bioma esteve associado a grandes projetos governamentais de modernização agricola (SILVA, 2019). O potencial agrícola do Cerrado se constituiu de forma mais efetiva após a criação da Empresa Brasileira de Pesquisa Agropecuária (Embrapa) na década de 1970 e dos estudos relacionados à inserção dessa região considerada como periférica, no mercado de produção de commodities para o mercado interno e externo (Embrapa, 1977; DALL'AGNOL, 2016). Por meio da Lei 5.851, em 07 de dezembro de 1972. o Poder Executivo do Brasil, representado pelo Presidente Emílio Garrastasu Médici, autorizava a criação da Embrapa. No ano seguinte, por meio do Decreto 72.020 de 28 de março de 1973 a Embrapa foi instituida, absorvendo a estrutura do extinto Departamento Nacional de Pesquisa e Experimentação Agropecuária (DNPEA).

A partir da criação da Embrapa centros de pesquisas foram criados, com enfoque em produtos e estudos das potencialidades agricolas regionais. O modelo utilizado para a criação dos centros de pesquisa se fundamentava em unidades de investigação com as seguintes caracteristicas: (i) centros de pesquisa para produtos agropecuários; (ii) centros de pesquisas temáticos; e (iii) centros de pesquisas ecorregionais (DALL'AGNOL, 2016). Em 1974 os primeiros centros foram criados os estudos especializados em gado de corte (Campo Grande, MS); seringueira (Manaus, AM); trigo (Passo Fundo, RS); arroz e feijão (Goiânia, GO). O Centro de Pesquisa Agropecuária dos Cerrados (CPAC) foi instituido em 1975 na cidade de Planaltina (DF), absorvendo a extinta Estação Experimental de Brasilia. Em 1977 ela publicou o seu primeiro relatório técnico para o periodo relativo a 1975-1976 (EMBRAPA, 1977), no qual apresentava dados e planejamentos para o desenvolvimento da agricultura na região compreendida como os cerrados, divulgando, inclusive, o mapa da distribuição desse ecossistema, como compreendido na época, com áreas de transição ecológica.

Desde a década de 1940 havia um grande incentivo a fim de ocupar os chamados "vazios populacionais" nas regiões de fronteira no CentroOeste e Norte do País. Mas foi durante os governos militares (1964-1985) que os biomas Cerrado e Amazônia passaram a serem vistos como zonas estratégicas para o desenvolvimento do País. A opção estratégica em delimitar os biomas, sobretudo considerando áreas privilegiadas para o desenvolvimento econômico do Brasil, teve como referências norteadoras as políticas nacionais de desenvolvimento (PNDs). A associação entre ciência e natureza fez parte do pacote institucional da Embrapa, que passou a conceber - Cerrado e a Amazônia como áreas estratégicas para a expansão da fronteira agrícola. No entanto, importantes estudos sobre os cerrados já estavam em andamento em importantes universidades brasileiras e estrangeiras (GODLAND, 1969; FERRI, 1943, 1944, 1955; FERRI; COUTINHO, 1958; FAISSOL, 
1953; FREITAS, MCCLUNG; LOTT, 1960; HUECK, 1957: WAIBEL, 1948). Esses estudos, além de identificar as potencialidades econômicas desse ecossistema, buscavam, sobretudo, identificar problemas relacionados à presença da carência de nutrientes e a de quantidade significativa de aluminio nos solos do Cerrado (GOODLAND, 1969). Assim, com base nesses estudos pioneiros as estratégias principais do pacote de modernização agrícola do Cerrado privilegiaram estudos sobre o manejo e a correção da acidez dos solos, a agregação de nutrientes com adubação por fertirrigação, aliados às infraestruturas logísticas de armazenamento de grãos e escoamento da produção.

Após a criação da Embrapa a pesquisa agropecuária brasileira precisou investir em melhoramento genético de cultivares agrícolas, que em muitos casos resultaram na "tropicalização" de linhagens como as da soja, por exemplo. Outros avanços tecnológicos visavam a inoculação de bactérias em cultivares para a captura de nitrogênio no solo, o que resultou em uma maior produtividade agricola com o uso menor de fertilizantes (VIEIRA FILHO, 2016).

No transcurso dos últimos anos, ocorreram profundas transformações econômicas, demográficas e socioculturais no conjunto do território nacional. Inicialmente, no final da década de 1940, os ideólogos pragmáticos da Nova Divisão Internacional do Trabalho, colocaram em prática a denominada "Revolução Verde", financiada por governos e instituições internacionais, a exemplo das fundações Ford e Rockefeller do Instituto Kellog (SILVA, 2013). Além dessas, outras fundações passaram a utilizar como laboratórios experimentais os espaços regionais favoráveis de determinados paises dependentes de capitais, ciência e tecnologia, com o intuito de avaliar o alcance dos resultados das pesquisas científicas e tecnológicas implementadas pósguerra. México, Índia, Filipinas, Ceilão, entre outras nações, são exemplos de cobaias nacionais e territoriais utilizadas como área de teste das novas pesquisas agroquimicas e agrotécnicas, em termos de uso de sementes selecionadas e geneticamente modificadas; aplicação de poderosos produtos agroveterinários destinados ao combate das pragas nas lavouras e pastagens, intencionalmente rotulados de "defensivos químicos" (PINGALI, 2012; EVENSON; GOLLIN, 2003); incorporação de novos adubos e fertilizantes, destinados à correção de solos portadores de carências minerais; emprego de técnicas agrícolas mais eficientes de manejo dos solos e de utilização dos recursos hídricos; utilização intensiva de equipamentos, máquinas, ferramentas e implementos agrícolas; plantio de espécies vegetais exóticas para a formação de pastagens; agregação de melhoria na reprodução genética do plantel de gado vacum, via seleção de matrizes e inseminação artificial etc.

A expansão da fronteira agrícola no Cerrado também agravou as questões agrárias e fundiárias no campo, sobretudo a partir da década de 1970. Dentre as consequências destacamos a presença de novos agentes da expansão agrícola nos chapadões centrais do Brasil. Esses novos agentes, dotados de capital e de novas tecnologias, instalaram-se em áreas de Cerrado em diferentes regiões, segundo os projetos de distribuir implementados pela Embrapa (1977). o processo não foi apenas de uma migração demográfica, mas também tecnológica e de infraestrutura, por meio de empresas agricolas e complexos agroindustriais, com destaque para os estados de Goiás, Mato Grosso e Mato Grosso do Sul. Esses novos agentes, denominados de forma geral como "gaúchos", tinham em comum a origem geográfica e étnica da expansão para - Brasil Central. Geralmente, em sua grande maioria, descentes de colonos italianos e alemães e produtores rurais do Sul do Brasil: gaúchos, paranaenses, catarinenses e paulistas.

Além desses, os novos pioneiros da expansão agricola eram compostos também por agentes locais e muitos estrangeiros estimulados a plantarem soja, milho, algodão, arroz, feijão e outras cultivares. Estimulados pelos projetos e incentivos financeiros carteira creditícia do Banco do Brasil para a produção no Cerrado, a nova fronteira agricola expandiu em busca novas terras agricultáveis. Os relatórios da Embrapa 
Cerrado - Centro de Pesquisa Agropecuária dos Cerrados (CPAC) - realizados entre 1975 a 1995. descrevem a adesão dessa empresa de pesquisa ao projeto Programa Para o Desenvolvimento do Cerrado (POLOCENTRO), cuja filosofia de atuação baseava-se na integração dos territórios dos Cerrados ao esforço produtivo do setor primário, em consonância com a política agrícola do II Plano Nacional de Desenvolvimento (EMBRAPA, 1977).

Entre as décadas de 1980 e 1990 o Cerrado se firmou com uma importante fronteira agricola, produtora de commodities e cultivares fundamentais para a expansão da balança comercial brasileira. Dentre os fatores responsáveis por uma revolução na produção agricola no Brasil foi a introdução da técnica de calagem, que havia transformado a acidez do solo do Cerrado em terras férteis para a agricultura. Ao mesmo tempo, a pesquisa agropecuária brasileira precisou investir em melhoramento genéticos de cultivares agrícolas, que em muitos casos favoreceu para a "tropicalização" de sementes como a soja. Outros avanços tecnológicos são destacados como por exemplo a inoculação de bactérias na semente para a captura de nitrogênio no solo, o que resultou em uma maior produtividade com o um menor de fertilizantes (VIEIRA FILHO, 2016).

Os projetos governamentais implementados a partir da década de 1970, desta forma, passaram a adotar como práticas para a modernização da agricultura no Cerrado o uso de fertilizantes em larga escala, baseando-se na produção de commodities valorizadas no mercado interno e externo para a produção de carne (soja e milho), e o incentivo na utilização de elementos que já havia uma difusão nas décadas anteriores como o uso de agrotóxicos e maquinários agrícolas. O saldo negativo do projeto governamental de expansão da fronteira agrícola no Brasil pode ser identificado nos sucessivos impactos socioambientais, no qual podemos destacar: a fragmentação da estrutura geológico-geomorfológica como embasamento físico do território; a degradação e a destruição da cobertura vegetal como protetora do solo e do subsolo; a redução da biodiversidade animal, vegetal e genética em espécies, nichos e ecossistemas, como reprodutora da vida; o assoreamento e a diminuição da rede de drenagem de superficie e subterrânea, das cabeceiras dos cursos d'água, das veredas, berço das águas, com suas matas ciliares ripárias, seus buritizais e suas vegetações campestres; a destruição das vocações culturais centenárias das comunidades interioranas; a destruição de monumentos naturais e sítios arqueológicos milenares.

Em suma, podemos considerar que parte significativo do patrimônio natural, biótico e cultural do Cerrado tem sido ameaçado pela lógica do modelo de expansão da fronteira adotado nas últimas décadas. O setor produtivo agrícola, por sua vez comemora os impressionantes índices de produtividade alcançados no Cerrado, sobretudo a partir da primeira década do século XXI. E nesse cenário, o destaque em produtividade e em ganhos reais de capital é liderado pela produção de soja (DALL'AGNOL, 2016; DALL'AGNOL, CARNEIRO FILHO; COSTA, 2016; DOMINGUES; BERMANN, 2012).

\section{A fronteira da soja no Cerrado}

A soja é uma cultivar de valor nutricional inquestionável e dotada de uma versatilidade comercial impressionante (CARRÃO-PANIZZI; MANDARINO, 1998; FRIEDMAN; BRANDON, 2001). A soja cultivada (Glycine max (L.) Merr.) pertence à familia Fabaceae, reconhecida por leguminosas oleaginosas. Em relação às suas raízes, podemos considerar que são subsuperficiais, cuja extensão do sistema radicular poder sofrer variações segundo as condições ecológicas as quais a planta estiver sujeita. Em termos de profundidade a raiz principal pode atingir até dois metros de profundidade. As raízes laterais, por sua vez, podem atingir até 2,5 metros, em condições adequadas de solo e clima (VERNETTI; GASTAL, 1979). Considerando as questões ambientais de esta cultivar exótica no Cerrado, e a rápida expansão desta sobre áreas de pastagem degradada e sobre áreas nativas do bioma, a utilização dessa cultivar exige cuidadoso estudo, principalmente quando esta planta ocupa locais estratégicos do ponto de vista ambiental e substitui plantas com sistemas radiculares complexos. 
Por isso o plantio deverá seguir normas rígidas de zoneamento ecológico e de planejamento ambiental, para que elementos importantes da ecologia regional sejam preservados.

O primeiro registro sobre a presença da soja no Brasil foi em 1882, quando o pesquisador Gustavo D'Utra utilizou material genético da soja na região do Recôncavo Baiano. E o primeiro cultivo comercial da soja ocorreu na região de Santa Maria, Rio Grande do Sul, em 1914. No entanto, o primeiro registro estatístico no Brasil de produção de soja é datado de 1941 , quando o Anuário Agrícola do Rio Grande do Sul apresentava a produção de 457 toneladas de grãos. Entre as décadas de 1950 a 1960 as pesquisas e produção de soja se concentravam no Sul do Brasil. Um acordo entre os Estados Unidos e o Brasil - conhecido como convênio EmbrapaUSAID/Wisconsin - em meados da década de 1960 permitiu a vinda de pesquisadores norteamericanos que passaram a pesquisar cultivares comerciais para o seu cultivo no Brasil (BONATO; BONATO, 1987, MINOR, 1975).

Em 1974 um grupo de trabalho, coordenado pelo pesquisador Amélio Dall'Agnol, trabalho no anteprojeto para a criação de um centro nacional de pesquisa da soja. Assim, em 1975 foi criada a Embrapa Soja, interessa no desenvolvimento dessa cultivar no Brasil e com vistas na crescente demanda mundial pelo produto. A cidade de Londrina, no norte do Paraná, foi o local escolhido para abrigar o grupo de trabalho e posteriormente a Embrapa Soja. E além dos vários pesquisadores do Sul e Sudeste do Brasil, a unidade em Londrina recebeu três pesquisadores Glen Gray Davis, Paul Spiegle Lehman e Roger Gordon Hanson, vinculados ao projeto Embrapa-USAID/Wisconsin (MINOR, 1975; MIYASAKA; MEDINA, 1981).

As primeiras ocorrências sobre a expansão da soja no Cerrado aparecem em registros a partir da década de 1970. Ao mesmo tempo, nessa década a soja se consolidou como a principal cultivar na produção de grãos no Brasil. Dentre os fatores estava a valorização do preço da oleaginosa no mercado mundial de grãos. Também foi o periodo em que ocorreu uma expansão da fronteira agrícola do Sul para os chapadões centrais do Brasil. A migração "gaúcha" foi motivada, sobretudo, pela dificuldade em ampliar a área plantada nos estados sulistas do Brasil, em face à valorização fundiária das terras no Sul e Sudeste. Além dos preços mais atrativos das terras do Brasil Central, a política nacional de créditos agricolas e as pesquisas em andamentos sobre o manejo do solo do Cerrado - sobretudo as pesquisas da Embrapa - favoreceram a imigração e a aquisição de áreas para o cultivo nos chapadões centrais brasileiros. Também, as pesquisas de melhoramento genético dessa cultivar para as condições tropicais do Cerrado, muito específicas em relação ao clima e ao solo do Brasil Central, contribuiram significativamente, a partir da incorporação de "caracteristicas genéticas (periodo juvenil longo) que inibem o florescimento precoce da soja em condições de baixa latitude, resultando em cultivares perfeitamente adaptadas às condições do Cerrado" (DALL'AGNOL, 2016, p. 26)

Considerando o conjunto de variáveis sobre a conjuntura da expansão da fronteira da soja, a partir da década de 1970 o Cerrado passou a ser a grande fronteira agricola no Brasil, com expansão, inclusive para áreas da Amazônia Legal (DOMINGUES; BERMANN, 2012). E considerando as potencialidades do Brasil em expandir a produção, a incorporação de áreas e o aumento da produtividade, o Cerrado passou a ser o espaço privilegiado para a fronteira da soja. Outro fator que deve ser considerado para o avanço da produção da soja foi o aumento mundial do consumo de carne (bovina, suina e aves), no qual a soja figura como insumo principal na produção de rações (CARNEIRO FILHO; COSTA, 2016; DOMINGUES; BERMANN, 2012, BONATO; BONATO, 1987).

Estudos recentes apresentam a soja como uma cultivar com resultados altamente positivos na incorporação econômica do Cerrado no projeto nacional de inserção regional. Para o setor produtivo ligado ao agronegócio, o Cerrado tem a aptidão necessária e capacidade de absorver uma agricultura moderna e se tornar em um dos principais celeiros agricolas nas próximas 
décadas (CARNEIRO FILHO; COSTA, 2016). O discurso da expansão da fronteira agricola no Cerrado utiliza, a priori, fundamentos sustentáveis do incremento de áreas agricultáveis e de aumento de produtividade. Para alguns desses estudos, o aumento da produção de soja não gerou impactos no Cerrado, na medida em que a fronteira agricola dessa oleaginosa ocupou áreas degradadas de pastagens e antropizadas (CARNEIRO FILHO; COSTA, 2016; DOMINGUES; BERMANN, 2012). No entanto, os desafios e os impactos da expansão da soja sobre o Cerrado são preocupantes. Principalmente, pelo desconhecimento do valor ambiental do Cerrado com um ecossistema complexo em termos geológicos, geomorfológicos, biológicos, entre outros, com uma história ambiental de longa duração e que estabeleceu nos chapadões centrais do Brasil um sistema biogeográfico que é fundamental para os demais ecossistemas que o circundam.

Em artigo publicado na revista Nature em 2017 (STRASSBURG et al., 2017), o pesquisador Bernardo Strassburg e outros, chamavam a atenção da comunidade científica para a comemoração da aparente redução nas taxas de desmatamento da Amazônia em torno de 70\% entre 2005 a 2013. O estudo afirmava, no entanto, que essa alegria efêmera era ofuscada pelo dramático desflorestamento do Cerrado. Os pesquisadores alertavam para uma extinção global sem precedentes na história, de 200 milhões de hectares da grande savana tropical brasileira. A principal causa dessa grande ameaça ecológica era creditada à dinâmica avassaladora da expansão da fronteira agrícola.

O fato é que a expansão da fronteira da soja está associada a impactos ambientais irreparáveis. Uma breve história ambiental do Cerrado não pode desconsiderar os estudos relativos à biodiversidade e aos avanços tecnológicos sobre a aptidão agrícola do Cerrado. E esse é o principal desafio para o desenvolvimento sustentável desse sistema biogeográfico. Os estudos científicos e a expansão demográfica e econômica da fronteira agrícola a partir da década de 1970 favoreceram a expansão da produção de grãos no Cerrado. E a soja ocupa um papel protagonista nessa história ambiental. Regiões como o MATOPIBA (área de intercessão entre os estados do Maranhão, Tocantins, Piauí e Bahia), por exemplo, evidenciam que o plantio dessa cultivar ocorreu de forma indiscriminada (DUTRA E SILVA et al, 2018). Dentre os fatores de maior impacto destacamos o uso indiscriminado dos recursos hídricos do Cerrado. O sistema de irrigação foi dinamizado, permitindo o cultivo durante todo ano, inclusive na estação seca. Muitos desses chapadões tabulares, também descritos como campinas - ambientes de relevo plano, vegetação rasteira e altitudes que oscilam entre 900 a 1000 metros acima do nivel do mar - são os principais responsáveis pela recarga dos aquíferos do continente sul-americano. A vegetação desses chapadões possui um sistema radicular peculiar responsável pela absorção das águas das chuvas e a geomorfologia plana contribui para o escoamento seja restrito, facilitando a absorção e o abastecimento dos aquiferos (BORGHETTI, 2004; RIBEIRO, 2008).

Os impactos da soja também geraram impactos fundamentais na biodiversidade do Cerrado. Essa cultivar exótica, na medida em que passou a ser introduzida e seu cultivo disseminado, trouxe para o ecossistema dos chapadões centrais vários tipos de insetos e larvas simbióticas que se associaram a alguns insetos e larvas nativas. A utilização indiscriminada de agrotóxicos e destruição da biodiversidade que coevoluiu com o Cerrado foi outro impacto da fronteira agrícola no Brasil Central. Isto desencadeou um processo acelerado de desequilíbrio, acabando com a fauna nativa de modo geral, incluindo as abelhas indigenas sem ferrão, da subfamilia Meliponinae, sendo conhecidos também como meliponineos (ROUBIK, 1989; VENTURIERI, 2008). As plantas nativas que tentavam rebrotar, através das raízes, eram combatidas com herbicidas especificos. A utilização desses agentes provocou a contaminação do solo, depois a contaminação das águas subterrâneas e depois a contaminação das próprias águas superficiais (PROCOPIO, 2008). 
Os principais impactos advindos da expansão da fronteira agrícola da soja sobre o bioma Cerrado podem ser assim caracterizados: a redução dos niveis dos aquiferos em decorrência da retirada da cobertura vegetal; a redução do patrimônio genético e potencial farmacêutico por meio da destruição de comunidades vegetais; a modificação radical do solo, por meio de uso de corretivos, fertilizantes e insumos, que poderão extinguir espécies que se adaptaram ao solo do Cerrado; a extinção de animais endêmicos, fundamentais para o equilibrio ecológico do bioma, por meio do uso indiscriminado do uso de herbicidas e inseticidas; e a contaminação do solo e dos lençóis freáticos pela utilização indiscriminada de agrotóxicos (BARBOSA, 2011; SANTOS; KOIDE, 2006).

\section{Considerações finais}

O Cerrado dos chapadões centrais do Brasil, se nos apresenta como um sistema biogeográfico, que envolve vários subsistemas e que se desenvolveu a milhões de anos, sendo um dos ecossistemas mais antigos do planeta. Esses subsistemas se diferenciam por solos, fisionomia vegetal, quantidade de água nos lençóis, comunidades animais, dentre outros. E qualquer modificação nos elementos dos subsistemas, provoca modificações no sistema biogeográfico do Cerrado na sua totalidade.

Em termos geológicos, o Cerrado pode ser considerado como uma das matrizes ambientais mais antigas da história recente do planeta, iniciada no período Cenozoico. Nesse sentido, podemos considerar que esse sistema biogeográfico já alcançou o seu clímax evolutivo, e que uma vez degradado, não haveria uma recuperação que pudesse abarcar a plenitude de sua biodiversidade. A grande maioria das espécies vegetais do Cerrado é formada por plantas de desenvolvimento lento. Algumas dessas espécies podem levar séculos para atingir a sua fase de maturidade, o que pode ser um indicador de extinção de espécies na medida em que trabalho de recomposição vegetal torna-se extremamente difícil face a todos os efeitos da expansão agricola no solo, nos recursos hidricos e na biodiversidade. Sem mencionar que estas plantas estão condicionadas a um tipo de solo oligotrófico (pobre em nutrientes minerais) com balanço hídrico específico, fato hoje difícil de ser encontrado em equilibrio no bioma Cerrado.

O Cerrado é uma realidade biofísica repleta de desafios, como qualquer outro ecossistema. Desafios que exigem dos historiadores ambientais, envolvidos nos estudos do Cerrado, um posicionamento ainda mais atento para um fenômeno histórico eminente, em que os processos de expansão agricola caminham em direção à rápida transformação das paisagens naturais e na extinção de espécies desse importante sistema biogeográfico.

\section{Referências}

AB'SABER, Aziz Nacib. The natural organization of Brazilian inter-and subtropical landscapes. Revista do Instituto Geológico, São Paulo, 21 (1/2), 57-70, 2000.

ADAM, Thomas (ed.). Germany and the Americas. Culture, politics, and history: a multidisciplinar encyclopedia. V. I. Santa Barbara: California, 2005.

ASSAD, E. D. (Coord.). Chuva nos Cerrados: análise e espacialização. Planaltina, DF: Embrapa-CPAC / Brasilia: Embrapa-SPI, 1994.

BACHELET, C. Pré-história no Cerrado: Análises antropológicas dos abrigos de Santa Elina e da Cidade de Pedra (Mato Grosso). Fronteiras: Journal of Social, Technological and Environmental Science, Anápolis-Goiás, v.3, n.2, p.96-110, jul.-dez. 2014.

BARBOSA, Altair Sales. Andarilhos da claridade: os primeiros habitantes do Cerrado. Goiânia: UCG, Intituto do Trópico Subúmido, 2002.

BARBOSA, Altair Sales. Cerrado: "Dor Fantasma" da biodiversidade brasileira. Revista do Instituto Humanitas Unisinos, São Leopoldo, Edição 382, p. 11-15, nov. 2011.

BARBOSA, Altair Sales. O livro da terra. Goiânia: Kelps, 2019.

BONATO, E.R.; BONATO, A.L.V. A soja no Brasil: história e estatística. Londrina: EMBRAPA-CNPSo, 1987. (EMBRAPA-CNPSo. Documentos, 21)

BORGHETTI, N. R. Aqüifero Guarani: a verdadeira integração dos paises do MERCOSUL. Curitiba, PR, 2004.

BROOKS, M.L.; D'ANTONIO, C.M.; RICHARDSON, D.M.; GRACE, J.B.; KEELEY, J.E.; DITOMASO, J.M.; HOBBS, R.J.; PELLANT, M.; PYKE, D. Effects of invasive alien plants on fire regimes. Bioscience, 54(7), p. 677-688, 2004. 
CAMARGO, A. J. A. de; CAMARGO, W. R. F. de; CORREAA, D. do C. V.; VILELA, M. de F.; AMORIM, F. W. Mariposas polinizadoras do cerrado: identificação, distribuição, importância e conservação. Planaltina, DF: Embrapa Cerrados, 2018.

CARRÃO-PANIZZI, M. C.; MANDARINO, J. M. G. Soja: Potencial de Uso na Dieta Brasileira. Londrina: EMBRAPA-CNPSo, 1998. 16p. (EMBRAPA-CNPSo. Documentos, 113)

COUTINHO, Leopoldo Magno. Aspectos ecológicos do fogo no Cerrado. II - As queimadas e a dispersão de sementes em algumas espécies anemocóricas do estrato herbáceo-subarbustivo. Bol. Botânica, Univ. São Paulo 5, p. 57-64, 1977

COUTINHO, Leopoldo Magno. O cerrado não é um bioma. Biota Neotrop. 11 (1), p. 21-24, 2011

COUTINHO, Leopoldo Magno. O conceito de bioma Acta bot. bras. 20(1), p. 13-23. 2006.

CRONON, W. Nature's Metropolis: Chicago and the Great West. New York: W. W. Norton \& Co., 1991.

CROSBY, Alfred W. Ecological Imperialism. The Biological Expansion of Europe, 900-1900. New York: Cambridge University Press, 2009

CROSBY, Alfred W. The Columbian Exchange. Biological and Cultural Consequences of 1492. Westpost, Conn: Greenwood Press, 1972.

DALL'AGNOL, Amélio. A Embrapa Soja no contexto do desenvolvimento da soja no Brasil: histórico e contribuições. Brasilia, DF: Embrapa, 2016.

DALL'AGNOL; CARNEIRO FILHO, Arnaldo; COSTA, Karine. A expansão da soja no Cerrado: caminhos para a ocupação territorial, uso do solo e produção sustentável. São Paulo: Agroicone, INPUT, 2016.

DEAN. W. With broadax and firebrand: the destruction of the Brazilian Atlantic Forest. Berkeley, Los Angeles, London: University of California Press, 1995

DOMINGUES, Mariana Soares; BERMANN, Célio. O arco de desflorestamento na Amazônia: da pecuária à soja. Ambiente e Sociedade, v. XV, n. 2, p. 1-22, maio-ago., 2012

DRUMMOND, J. A. A história ambiental: temas, fontes e linhas de pesquisa. Estudos Históricos, v.4, n.8, p.177-97, 1991.

DUTRA E SILVA, S. No Oeste, a terra e o céu: a expansão da fronteira agrícola no Brasil Central. Rio de Janeiro: Mauad X, 2010.

DUTRA E SILVA, S.; MATEUS, R.; BRAZ, V.; PEIXOTO, J. A Fronteira do Gado e a Melinis Minutiflora P. Beauv. (POACEAE). Sustentabilidade em Debate, 6(2), 17-32, 2015. https://doi.org/10.18472/SustDeb. v6n2.2015.15469

DUTRA E SILVA, S.; BOAVENTURA, K.J.; PORFÍRIO JÚNIOR, E.D.; SILVA NETO, C. M. A última fronteira agrícola do Brasil: o Matopiba e os desafios de proteção ambiental no Cerrado. Estudios Rurales, Buenos Aires, v. 8, n. Especial (Octubre), CEAR-UNQ, p. 145-178, 2018
EMBRAPA. Base de Dados da Pesquisa Agropecuária Sistema EMBRAPA de Bibliotecas - SEB, Brasília, DF

EMBRAPA. Centro de Pesquisa Agropecuária dos Cerrados. Relatório técnico anual do 1975-1976. Planaltina, DF, 1977

EVENSON, R.E., GOLLIN, D. Assessing the Impact of the Green Revolution, 1960 to 2000 . Science 300.5620, p. 758-62, 2003. 10.1126/science.1078710

FAISSOL, S. Vegetação e solos no sudeste do Planalto Central. Rio, CNG, p. 15, 1953

FERREIRA, M. E; FERREIRA JR, L.G.; LATRUBESSE, E.M; MIZIARA, F. Considerations about the land use and conversion trends in the savanna environments of Central Brazil under a geomorphological perspective. Journal of Land Use Science, 11:1, p. 33-47, 2016. 10.1080/1747423X.2013.845613

FERRI, M.G.; COUTINHO, L.M. Contribuição ao conhecimento da ecologia do cerrado. Estudo comparativo da economia d'agua; da sua vegetação em Emas (Est. São Paulo), Campo Grande (Est. Mato Grosso), e Goiânia (Est. Goias). Bol. Fac. Fil. Cien. Letr. U.S.P., 224 15. p. 103-150, 1958.

FERRI, M.G. Contribuição ao conhecimento da ecologia do cerrado e da caatinga. Bol. Fac. Fil. Cien. Letr. U.S.P., 195, 12, p. 1-170, 1955.

FERRI, M.G. Observações sobre Lagoa Santa. Ceres, 4. p. 1-16, 1943.

FERRI, M.G. Transpiração de plantas permanentes dos cerrados. Bol. Fac. Fil. cien. Letr. U.S.P. 41, Bot. 4, p. 159-224, 1944.

FLORA BRASILIENSES. 2005, Centro de Referência em Informação Ambiental, CRIA. Sistema hospedado no Internet Data Center da Rede Nacional de Ensino e Pesquisa, RNP. Flora Brasiliensis On-line, 2005

FREITAS, L.M.M. DE; MCCLUNG, A.C.; LOTT, W.L. Field studies on fertility problems of two Brazilian cerrados. IBEC, Res. Inst. 21, p. 28, 1960.

FRIEDMAN, Mendel; BRANDON, David L. Nutritional and Health Benefits of Soy Proteins. J. Agric. Food Chem., v. 49, n. 3, p 1069-1086, 2001.

GALVÃO, V.M. Clima. In: FUNDAÇÃO IBGE. Geografia do Brasil. Grande região Centro-Oeste. Rio de Janeiro, IBGE, v.4, p. 71-118, 1960.

GALVÃO, V.M. Regiões bioclimáticas. In: FUNDAÇÃO IBGE. Atlas Nacional do Brasil. Rio de Janeiro, IBGE, 1962.

GARDNER, George. Viagem ao interior do Brasil, principalmente nas provincias do Norte e nos distritos do ouro e do diamante durante os anos de 1836-1841. Belo Horizonte: Ed. Itatiaia; São Paulo: Editora da Universidade de São Paulo, 1975.

GIUSTINA, C.C.D. 2013. Degradação e conservação do cerrado: uma história ambiental do estado de Goiás. Tese (Desenvolvimento Sustentável) - Centro de Desenvolvimento Sustentável, Universidade de Brasilia, Brasilia, 2013 
GIUSTINA, C.C.D.; DUTRA E SILVA, S.; MARTINS, E.S. Geographic reconstruction of a Central-West Brazilian landscape devastated during the first half of the 20th century: Mato Grosso de Goiás. Sustentabilidade em debate, v. 9, n.3, p. 44-63, 2018. 10.18472/SustDeb. vgn3.2018.18588

GLACKEN, C.J. Traces on the Rhodian Shore: Nature and Culture in Western Thought from Ancient Times to the End of the Eighteenth Century. Berkeley: University of California Press, 1967

GODLAND, Robert. Ecological study of Cerrado vegetation of South-Central Brazil. Thesis, Ph.D., Botany Department. Faculty of Gradute Studies and Research of McGill University. McGill University, Montreal, Canada, 1969.

GOMES, L., MARACAHIPES, L., MARIMON, B.S., REIS, S.M., ELIAS, F., MARACAHIPES-SANTOS, L., MARIMON-JUNIOR, B.H., LENZA, E., Post-fire recovery of savanna vegetation from rocky outcrops. Flora Morphol. Distrib. Funct. Ecol. Plants, v. 209, n. 3-4, p. 201-208, 2014

GOMES, L., MIRANDA, H., BUSTAMANTE, M. How can we advance the knowledge on the behavior and effects of fire in the Cerrado biome? For. Ecol. Manage. 417, p. 281-290, 2018.

GOMES, Maria do Carmo Andrade. A canção das palmeiras: Eugenius Warming, um jovem botânico no Brasil. Estudo crítico de Birgitte Holten e Michael Sterll. Belo Horizonte: Fundação João Pinheiro, Centro de Estudos Históricos e Culturais, 2006.

GOTTSBERGER, G. Beetle pollination and flowering rhythm of Annona spp. (Annonaceae) in Brazil. Plant Syst. Evol., 167, p. 165-187, 1989

GOTTSBERGER, G., SILBERBAUER-GOTTSBERGER, I. Life in the Cerrado: a South American Tropical Seasonal Vegetation, Vol. II. Pollination and seed dispersal. Reta Verlag, Ulm, 2006.

GOTTSBERGER, Gerhard. Generalist and specialist pollination in basal angiosperms (ANITA grade, basal monocots, magnoliids, Chloranthaceae and Ceratophyllaceae): what we know now. Plant Div. Evol., v. 131/4, p. 263-362, 2016

GRABHERR, G.; KOJIMA, S. Vegetation Diversity and Classification Systems. In: A.M. Solomon \& H.H. Shugart (ed.). Vegetation Dynamics \& Global Change. New York, Chapman \& Hall, 1993, p 218-232.

HARGREAVES, G.H. Climate and irrigation requirements for Brazil. Utah State University, USA, 1976

HENNESSY, Alistair. The Frontier in Latin American History. Londres: Edward Arnold, 1978.

HENRIQUES, R.P.B. Influência da história, solo e fogo na distribuição e dinâmica das fitofisionomias no bioma do Cerrado. In: SCARIOT, A., SOUSA-SILVA, J.C., FELFILI, J.M. (ed.). Cerrado: Ecologia, Biodiversidade e Conservação. Ministério do Meio Ambiente, Brasilia, 2005, p. 73-92.
HERBÁRIO VIRTUAL AUGUSTE DE SAINT-HILAIRE. Instituto de Botânica, Muséum National d'Histoire Naturelle, Institut des Herbiers Universitaires, Centro de Referência em Informação Ambiental, Fundação de Amparo à Pesquisa do Estado de São Paulo, Fundação Vitae. Disponivel em: http://hvsh.cria.org.br.

HOLANDA, Sérgio Buarque de. Visão do Paraíso: os motivos edênicos no descobrimento e colonização do Brasil. São Paulo: Companhia das Letras, 2010.

HUECK, K. Sobre a origem dos campos cerrados no Brasil e algumas novas observações no seu limite meridional. Rev. Bras. Geogr, 14, p. 67-82, 1957.

KARASCH, Mary. Before Brasilia: Frontier Life in Central Brazil. University of New York Press, 2016.

KLEIN, Aldo Luiz. Eugen Warming e o cerrado brasileiro: um século depois. São Paulo: Editora UNESP, Imprensa Oficial do Estado, 2002.

KURY, L.B. Viajantes e naturalistas do século XIX. In: PEREIRA, P. R.(org). Brasiliana da Biblioteca Nacional - Guia de fontes sobre o Brasil. Rio de Janeiro: Fundação Biblioteca Nacional, Nova Fronteira, 2001.

KURY, Lorelai Brilhante. Auguste de Saint-Hilaire, viajante exemplar. Intellèctus, Rio de Janeiro, 2 (1), p. 1-11, 2003.

LAUX, J. H.; PIMENTEL, M. M.; DANTAS, E. L.; ARMSTRONG, R.; JUNGES, S. L.; Two Neoproterozoic crustal accretion events in the Brasilia Belt, central Brazil. Journal of South American Earth Sciences, 18, p. 183$198,2005$.

MARTINS, Marcos Lobato. História e Meio Ambiente. São Paulo: Annablume, 2007.

MARTIUS, Carl Friedrich Phillip von. The book of palms. Köln: Taschen, 2015

McCREERY, D. Frontier Goiás, 1822-1889. Stanford: Stanford University Press, 2006.

McNEIL, J.R; ENGELKE, P. The great acceleration: na environmental history of the antropocene since 1945 Cambrigde, Massachusetts: The Belknap Press of Harvard, 2014.

MINOR, H.C. End of tour report: soybean research program EMBRAPA/USAID/Wisconcin Loan agrément 512-L-077. Brasilia, DF: EMBRAPA, 1975.

MIRANDA, H.S.; BUSTAMANTE, M.M.C.; MIRANDA A.C. The fire fator. In: OLIVEIRA, P.S.; MARQUIS, R.J. (org.). The cerrados of brazil: ecology and Natural History of a Neotropical Savanna. Columbia University Press, 2002, p. 51-68.

MIYASAKA, S.; MEDINA, J.C. (ed.) A soja no Brasil. Campinas, ITAL, 1981.

NATURAL HISTORY MUSEUM OF DENMARK LIBRARY, BOTANICAL \& GEOLOGICAL SECTION. University of Copenhagen, Dinamarca.

NEVES, B. B.N., CORDANI, U.G. Tectonic evolution of South America during the late Proterozoic. Precambrian Research, 53, p. 23-40, 1991. 
OLIVEIRA, A.M.F. A diversidade paisagistica das savanas brasileiras nas iconografias de Florence e de Martius: alguns aspectos do Cerrado da primeira metade do século XIX. História Revista, v. 22, n. 2, p. 144-166, 2017.

PÁDUA, José Augusto. As bases teóricas da história ambiental. In: FRANCO, J.L.A; DUTRA E SILVA, S.; DRUMMON, J.A.; TAVARES. G.G. História ambiental: fronteiras, recursos naturais e conservação da natureza, editado por. Rio de Janeiro: Garamond, 2012, p. 17-37.

PEIXOTO, J.C.; NEVES B.J.; VASCONCELOS, F.G.; NAPOLITANO, H.B.; BARBALHO, M.G.S.; DUTRA E SILVA, S.; ROSSETO, L.P. Flavonoids from Brazilian Cerrado: Biosynthesis, Chemical and Biological Profile. Molecules. 24(16), aug. 2019. 10.3390/molecules24162891

PINGALI, P. L. Green revolution: impacts, limits, and the path ahead. Proceedings of the National Academy of Sciences of the United States of America, vol. 109, 31, p. 12.302-12.308, 2012.

POHL, Johann Emanuel. Viagem ao interior do Brasil. Belo Horizonte: Ed. Itatiaia; São Paulo: Editora da Universidade de São Paulo, 1976.

PROCOPIO, S. de O., et al. Fitorremediação de solo contaminado com picloram por capim-pé-de-galinha-gigante (Eleusine coracana). Rev. Bras. Ciênc. Solo, Viçosa, v. 32, n. 6, p. 2517-2524, Dec. 2008.

RIBEIRO, Wagner Costa. Aqüifero Guarani: gestão compartilhada e soberania. Estud. av., São Paulo, v. 22, n. 64, p. 227-238, Dec. 2008

RIEDL-DORN, Christa. Johann Natterer e a Missão Austriaca para o Brasil. Petrópolis, RJ: Index, 1999.

ROUBIK, D.W. Ecology and natural history of tropical bees. New York, Cambridge Univ. Press, 1989.

SAINT-HILAIRE, Auguste de. Viagem à Província de Goiás. Belo Horizonte: Ed. Itatiaia; São Paulo: Editora da Universidade de São Paulo, 1975

SANO, E.E; ROSA, R.; BRITO, J.L.S.; FERREIRA, L.G. Mapeamento de cobertura vegetal do Bioma Cerrado: estratégias e resultados. Planaltina, DF: Embrapa Cerrados, 2007.

SANTOS, B. S. Pela mão de Alice. O social e o político na transição pós-moderna. São Paulo: Cortez, 1997.

SANTOS, Ronaldo Medeiros dos; KOIDE, Sergio. Avaliação da Recarga de Águas Subterrâneas em Ambiente de Cerrado com Base em Modelagem Numérica do Fluxo em Meio Poroso Saturado. RBRH, Revista Brasileira de Recursos Hidricos, v. 21, n.2, p. 451-451, abr./jun. 2016.

SILVA, C.M. da. Nelson Rockefeller e a atuação da American International Association for Economic and Social Development: debates sobre missão e imperialismo no Brasil, 1946-1961. Hist. cienc. saúde-Manguinhos [online], v.20, n.4, pp.1695-1711, 2013.

SILVA, Claiton Márcio. Between Fenix and Ceres: The Great Acceleration and the Agricultural Frontier in the Brazilian Cerrado. Varia hist., Belo Horizonte, v. 34, n. 65, p. 409-444, 2018
SILVA, Claiton Márcio. The barren side of Brazil: science, water resources, and the debate on the (in)fertile soils of the Brazilian cerrado, 1892-1942. História, Ciências, Saúde - Manguinhos, Rio de Janeiro, v. 26, n.2, abr.-jun. 2019.

SILVA, F.A.M. da; ASSAD, E.D.; STEINKE, E.T.; MÜLLER, A.G. Clima do Bioma Cerrado. In: ALBUQUERQUE, A.C.S, SILVA, A. G (org.). Agricultura tropical: quatro décadas de inovações tecnológicas, institucionais e políticas. Volume 1. Embrapa Informação Tecnológica, Brasilia, 2008

SOUZA, F. S. Na imensidão do Cerrado, a linldomável natureza: sertão, fronteira e viajantes em Goiás na primeira metade do século XIX. In: DUTRA E SILVA, S.; SÁ, D.M.; SÁ, M.R (org.) Vastos Sertões: história e natureza na ciência e na literatura. Rio de Janeiro: Mauad X, 2015

SPIX, Johann Baptist von; MARTIUS, Carl Friedrich Phillip von. Viagem pelo Brasil. Belo Horizonte: Ed. Itatiaia; São Paulo: Ed. Da Universidade de São Paulo, 1981.

STRASSBURG, B. N.; BROOKS, T.; FELTRAN-BARBIERI, R.; IRIBARREM, A.; CROUZEILLES, R.; LOYOLA, R.; LATAWIEC, A.E.; OLIVEIRA FILHO, F.J.B.; SCARAMUZZA, C.A.M.; SCARANO, F.R.; SOARES-FILHO, B.; BALMFORD, A. Moment of truth for the Cerrado hotspot. Nature Ecology \& Evolution 1, 0099, p. 1-3, 2017.

TURNER, F.J. The frontier in American history. Mineola Nova York: Dover Publications, 2010.

UCLA. Library Special Collections, Charles E. Young Research Library, University of California, Los Angeles.

VAN AUSDAL, S.; WILCOX R. W. Hoofprints: Ranching and Landscape Transformation. In: LEAL, C., PÁDUA, J. A.; SOLURI, J. New Environmental Histories of Latin America and the Caribbean. Münich: RCC Perspectives, 2013, n. 7, p. 73-79.

VENTURIERI, Giorgio Cristino. Criação de abelhas indigenas sem ferrão. Belém, PA: Embrapa Amazônia Oriental, 2008.

VERNETTI, F. de J.; GASTAL, M.F. da C. Descrição botânica da soja. Pelotas, Empresa Brasileira de Pesquisa Agropecuária, Unidade de Execução de Pesquisa de Âmbito Estadual de Pelotas, 1979. (EMBRAPA. UEPAE/Pelotas. Circular Técnica, 7)

VIERA FILHO, J. E. R. Expansão da fronteira agricola no Brasil: desafios e perspectivas. Instituto de Pesquisa Econômica Aplicada - Brasília: Rio de Janeiro: Ipea, 2016.

WAIBEL, Leo. A Vegetação e o Uso da Terra no Planalto Central. Revista Brasileira de Geografia, Ano X, n. 02, p. 335-380, 1948.

WARMING, Eugenius. Lagoa Santa. Et bidrag til den biologiske plantegeografi. Kopenhagen: Bianco Lunos Kgl. Hof-Bogtrykkeri, 1892.

WEBB, W.P. The great frontier. Reno, Las Vegas: University of Nevada Press, 2003. 
WILCOX, Robert W. Cattle in the backlands: Mato Grosso and the Evolution of Ranching in the Brazilian Tropics. AustIn: University of Texas Press, 2017.

WORSTER, Donald (ed.). The ends of the Earth: perspectives on modern environmental history. New York: Cambrigde University Press, 1988.

WORSTER, Donald. Under Western skies: nature and history in the American West. Nova York: Oxford University Press, 1992.

WULF, Andrea. The invention of nature: Alexander Von Humboldt's new world. New York: Alfred A. Knoft, 2015

\section{Sandro Dutra e Silva}

Doutor em História, Universidade de Brasília (UnB, Brasilia, DF, Brasil). Professor na Universidade Estadual de Goiás, Goiânia, GO, Brasil e no Centro Universitário de Anápolis (UNIEVANGELICA), Anápolis, GO, Brasil.

\section{Altair Sales Barbosa}

Doutor em Arqueologia Pré-Histórica, Smithsonian Institution, National Museum of Natural History, Washington DC. Professor no Centro Universitário de Anápolis (UniEVANGELICA); Anápolis, GO, Brasil.

\section{Endereço para correspondência}

Sandro Dutra e Silva

Av. Edmundo Pinheiro de Abreu, n. 423, Apto.101

Sector Bela Vista, 74823-344

Goiânia, GO, Brasil

Altair Sales Barbosa

Rodovia GO 020, Km 17, Condomínio Alta Vista

75264-712

Senador Canedo, GO, Brasil 